OPEN ACCESS

Edited by:

Soumyajit Roy,

Indian Institute of Science Education and Research Kolkata, India

Reviewed by:

Yoshihito Hayashi,

Kanazawa University, Japan

Venkataramanan Mahalingam, Indian Institute of Science Education and Research Kolkata, India

*Correspondence: Karolina Kniec k.kniec@intibs.pl Lukasz Marciniak I.marciniak@intibs.pl

Specialty section: This article was submitted to Inorganic Chemistry, a section of the journal Frontiers in Chemistry

Received: 19 April 2019 Accepted: 08 July 2019 Published: 23 July 2019

Citation: Kniec K and Marciniak L (2019) Different Strategies of Stabilization of Vanadium Oxidation States in $\mathrm{Lagao}_{3}$ Nanocrystals. Front. Chem. 7:520. doi: 10.3389/fchem.2019.00520

\section{Different Strategies of Stabilization of Vanadium Oxidation States in $\mathrm{Lagao}_{3}$ Nanocrystals}

\author{
Karolina Kniec* and Lukasz Marciniak* \\ Institute of Low Temperature and Structure Research, Polish Academy of Sciences, Wroclaw, Poland
}

The spectroscopic properties of $\mathrm{LaGaO}_{3}$, doped with $\mathrm{V}$ ions, were examined in terms of the possibility of the stabilization of particular vanadium oxidation states. It was shown that three different approaches may be applied in order to control the ionic charge of vanadium, namely, charge compensation, via incorporation of $\mathrm{Mg}^{2+} / \mathrm{Ca}^{2+}$ ions, citric acid (CA)-assisted synthesis, with various CA concentrations and grain size tuning through annealing temperature regulation. Each of utilized method enables the significant reduction of $\mathrm{V}^{5+}$ emission band at $520 \mathrm{~nm}$ associated with the $\mathrm{V}^{4+} \rightarrow \mathrm{O}^{2-} \mathrm{CT}$ transition in respect to the ${ }^{2} \mathrm{E} \rightarrow{ }^{2} \mathrm{~T}_{2}$ emission band of $\mathrm{V}^{4+}$ at $645 \mathrm{~nm}$ and ${ }^{1} \mathrm{E}_{2} \rightarrow{ }^{3} \mathrm{~T}_{1 \mathrm{~g}}$ emission band of $\mathrm{V}^{3+}$ at $712 \mathrm{~nm}$. The most efficient $\mathrm{V}$ oxidation state stabilization was obtained by the use of grain size modulation, which bases on fact of different localization of the $V$ ions of given charge in the nanoparticles. Moreover, the CA-assisted synthesis of $\mathrm{LaGaO}_{3}: \mathrm{V}$ determines $V$ valence states but also provides significant separation of the nanograins. It was found that superior charge compensation was achieved when $\mathrm{Mg}^{2+}$ ions were introduced in the matrix, due the more efficient lability, resulting from the comparable ionic radii between $\mathrm{Mg}^{2+}$ and $\mathrm{V}$ ions.

Keywords: vanadium, charge compensation, citric acid, luminescence, nanocrystals

\section{INTRODUCTION}

It is well-known that the electronic configuration of optically active ions and thus their spectroscopic properties depend strongly on the their oxidation state (Weber and Riseberg, 1971; Felice et al., 2001; Gupta et al., 2014; Matin et al., 2017; Drabik et al., 2018; Kniec and Marciniak, 2018a,b; Trejgis and Marciniak, 2018). These features may in turn be influenced by many factors, such as type of the lattice, in which the ions are embedded and coordination number of the substituted ion, synthesis method, size of phosphor grain etc. (McKittrick et al., 1999; Azkargorta et al., 2016; Marciniak et al., 2017; Kniec and Marciniak, 2018b; Zhang et al., 2018). The difference in the spectroscopic properties of optically active ions depending on the oxidation state in the case of lanthanides in especially well-manifested for europium ions, which may occur in two $2^{+}$and $3^{+}$oxidation states. Emission spectra of its trivalent ions consist of narrow lines attributed to intraconfigurational $\mathrm{f}-\mathrm{f}$ electronic transitions whose spectral position is almost independent on the type of host material. On the other hand emission of $\mathrm{Eu}^{2+}$ is characterized by broad d-d emission band of maxima which can be tuned by the modification of the crystal field strength (Peng and Hong, 2007; Mao et al., 2009; Mao and Wang, 2010; Sato et al., 2014; Zhang et al., 2015). Similar differences can be found in the case of transition metal (TM) ions, where electronic transitions between $\mathrm{d}$ states are responsible for luminescence. 
In turn the luminescence of TM on different oxidation state is conditioned by presence of either octahedral or tetrahedral local site symmetries, where the optically active ion is substituted (Grinberg et al., 2017; Cao et al., 2018; Elzbieciak et al., 2018). This points to the importance of the appropriate choice of the local ion's environment and thus the host material to obtain efficient luminescence. The valence state of TM influences their output color, what is the most frequently encountered in case of manganese and chromium ions (Brik et al., 2011; Cao et al., 2016, 2018; Elzbieciak et al., 2018). $\mathrm{Cr}^{3+}$ ions may reveal red and NIR luminescence ascribed to the ${ }^{2} \mathrm{E}_{\mathrm{g}} \rightarrow{ }^{4} \mathrm{~A}_{2 \mathrm{~g}}$ spin-forbidden and ${ }^{4} \mathrm{~T}_{2 \mathrm{~g}} \rightarrow{ }^{4} \mathrm{~A}_{2 \mathrm{~g}}$ spin-allowed transition and (Struve and Huber, 1985; Brik et al., 2016; Elzbieciak et al., 2018), whereas $\mathrm{Cr}^{4+}$ ions exhibit emission in NIR region (around 1,100 nm), which is attributed to the ${ }^{3} \mathrm{~A}_{2} \rightarrow{ }^{3} \mathrm{~T}_{1}$ transition (Devi et al., 1996). Different emission color is also observed for manganese ions, where $\mathrm{Mn}^{2+}, \mathrm{Mn}^{3+}$ and $\mathrm{Mn}^{4+}$ ions show blue $\left({ }^{4} \mathrm{~A}_{2} \rightarrow{ }^{4} \mathrm{~T}_{1}\right)$, yellow-orange $\left({ }^{4} \mathrm{~T}_{1 \mathrm{~g}} \rightarrow{ }^{6} \mathrm{~A}_{1 \mathrm{~g}}\right)$ or red $\left({ }^{5} \mathrm{~T}_{2} \rightarrow{ }^{5} \mathrm{E}\right)$ luminescence, respectively (Trejgis and Marciniak, 2018). This phenomenon is also observed for titanium ions, where $\mathrm{Ti}^{4+}$ and $\mathrm{Ti}^{3+}$ possess blue and red emission color, which related to the $\mathrm{O}^{2-} \rightarrow \mathrm{T}_{2}$ (CT, $\left.\lambda_{\text {em }} \sim 450 \mathrm{~nm}\right)$ and ${ }^{2} \mathrm{E}_{\mathrm{g}} \rightarrow{ }^{2} \mathrm{~T}_{2 \mathrm{~g}}\left(\lambda_{\text {em }} \sim 800 \mathrm{~nm}\right)$ transitions, respectively (Martínez-Martínez et al., 2005; Pathak and Mandal, 2011; Drabik et al., 2018). The possibility of charge modulation is not only interesting in terms of spectroscopic tunability but also to get rid of some valence states, being marked by toxic properties and reducing the potential biological deployment, which is very important in case of chromium and cobalt ions (Buzea et al., 2007; Chowdhury and Yanful, 2010; Wang et al., 2012; Scharf et al., 2014).

One of the least known transition metal ion, whose optical properties strongly depend on the oxidation state is vanadium. Several oxidation states of vanadium can be found like $\mathrm{V}^{5+}$, $\mathrm{V}^{4+}, \mathrm{V}^{3+}, \mathrm{V}^{2+}$ of the $3 \mathrm{~d}^{0}, 3 \mathrm{~d}^{1}, 3 \mathrm{~d}^{2}, 3 \mathrm{~d}^{3}$ electronic configuration, respectively. Recently we presented the potential application of $\mathrm{V}$ ions emission for luminescent nanothermometry, where $\mathrm{V}$ ions were incorporated into inorganic hosts, such as YAG $\left(\mathrm{Y}_{3} \mathrm{Al}_{5} \mathrm{O}_{12}\right)$ (Kniec and Marciniak, 2018b) and $\mathrm{LaGaO}_{3}$ (Kniec and Marciniak, 2018a). As it was shown its high susceptibility to the thermal changes enables to detect the local temperatures with satisfactory sensitivity (Kniec and Marciniak, 2018a,b). Depending on the host material different $\mathrm{V}$ oxidation states were found, namely $\mathrm{V}^{5+}, \mathrm{V}^{3+}$ and $\mathrm{V}^{5+}, \mathrm{V}^{4+}, \mathrm{V}^{3+}$, for $\mathrm{YAG}$ and $\mathrm{LaGaO}_{3}$ lattices, respectively. What is more, an immense impact of synthesis method and annealing temperature on crystalline size, dispersion factor of the particles, size distribution were presented (Kniec and Marciniak, 2018a,b), which in turn lead to the presence of different $\mathrm{V}$ valence states, characterized by distinct luminescent properties and susceptibility to changes of local ion environment. Due to good spectral separation of emission bands of particular oxidation states of vanadium ions the qualitatively verification of their presence can be done basing on the analysis of the luminescent properties of vanadium doped phosphor. The $\mathrm{V}^{5+}, \mathrm{V}^{4+}$, and $\mathrm{V}^{3+}$ luminescence is related with $\mathrm{V}^{4+} \rightarrow \mathrm{O}^{2-} \mathrm{CT}$ transition $\left(\lambda_{\mathrm{em}}=520 \mathrm{~nm}\right)$, broad band ${ }^{2} \mathrm{E} \rightarrow{ }^{2} \mathrm{~T}_{2}$ d-d electronic transition $\left(\lambda_{\mathrm{em}}=645 \mathrm{~nm}\right)$ and narrow line ${ }^{1} \mathrm{E}_{2} \rightarrow{ }^{3} \mathrm{~T}_{1 \mathrm{~g}} \mathrm{~d}$-d electronic transition $\left(\lambda_{\mathrm{em}}=712 \mathrm{~nm}\right)$, respectively (Ryba-Romanowski et al., 1999a; Kniec and Marciniak, 2018a,b).

In the course of our previous studies it was found that broad emission band of $\mathrm{V}^{5+}$ with the maxima at around $497 \mathrm{~nm}\left(\mathrm{~V}^{4+}\right.$ $\rightarrow \mathrm{O}^{2-} \mathrm{CT}$ emission) predominates in the emission spectra (Kniec and Marciniak, 2018a,b). However, as it was already proved the ${ }^{2} \mathrm{E} \rightarrow{ }^{2} \mathrm{~T}_{2}$ emission of $\mathrm{V}^{4+}$ ions is characterized by higher susceptibility to luminescence thermal quenching and hence reveals the best performance to non-contact readout. As it was already shown in the case of YAG nanocrystals, due to the spatial segregation of different vanadium oxidation states within the nanoparticle, the emission intensity ratio of $\mathrm{V}^{5+}$ to $\mathrm{V}^{3+}$ can be easily modulated through size of the nanoparticles. Moreover, the involvement of CA during the synthesis caused the reduction of oxidation state of vanadium substrate, namely from pentavalent to trivalent valence states, being observed by the changes of color of the solution, from yellow to blue, respectively (Kniec and Marciniak, 2018a,b). Citric acid is a complexing agent, which is highly soluble in polar solvents and widely used in the synthesis of nanoparticles, guaranteeing the incorporation of each metal into the material, maintaining local stoichiometry (Davar et al., 2013), which is possible due the presence of three carboxylic group $(-\mathrm{COOH})$ and one hydroxyl group $(-\mathrm{OH})$ in the CA chain (Gutierrez et al., 2015; Kniec and Marciniak, 2018a,b). It is well-known as a reducing and capping agent, providing possibility of charge modulation, nano-sized particles and relatively good size distribution, due the high chemical stability, steric impediment and generation of electrostatic repulsive forces (Zhang and Gao, 2004; Thio et al., 2011; Davar et al., 2013; Gutierrez et al., 2015; Shinohara et al., 2018). However, the addition of PEG, entering into polyesterification with $\mathrm{CA}$, leads to discoloration of the solution (Kniec and Marciniak, 2018a,b). This phenomenon may be explained as a decrease of reducing properties of CA, resulting from the interaction between carboxylic and hydroxyl group of CA and PEG, respectively. Another approach which was frequently used in terms of stabilization of oxidation state of vanadium ions in the crystals but never in the case of nanocrystals is charge compensation. In this paper the potential possibilities of the modulation of vanadium oxidation states by varying charge compensation process, annealing temperature and the choice of appropriate synthesis conditions have been presented. Employment of these modifications leads to the changes in vanadium valence states and in consequence modify spectroscopic properties, such as emission color.

\section{EXPERIMENTAL}

\section{$\mathrm{LaGaO}_{3}: \mathrm{V}$ Synthesis With Different Amounts of Citric Acid}

The $\mathrm{LaGaO}_{3}: \mathrm{xV}$ nanocrystals have been successfully synthesized by the use of citric acid assisted sol-gel method. The first steps of preparation were carried out analogously to the previous synthesis of $\mathrm{LaGaO}_{3}$ (see Table S1) (Kniec and Marciniak, 2018a). Lanthanum oxide $\left(\mathrm{La}_{2} \mathrm{O}_{3}\right.$ with $99.999 \%$ purity from Stanford Materials Corporation), gallium nitrate nonahydrate 

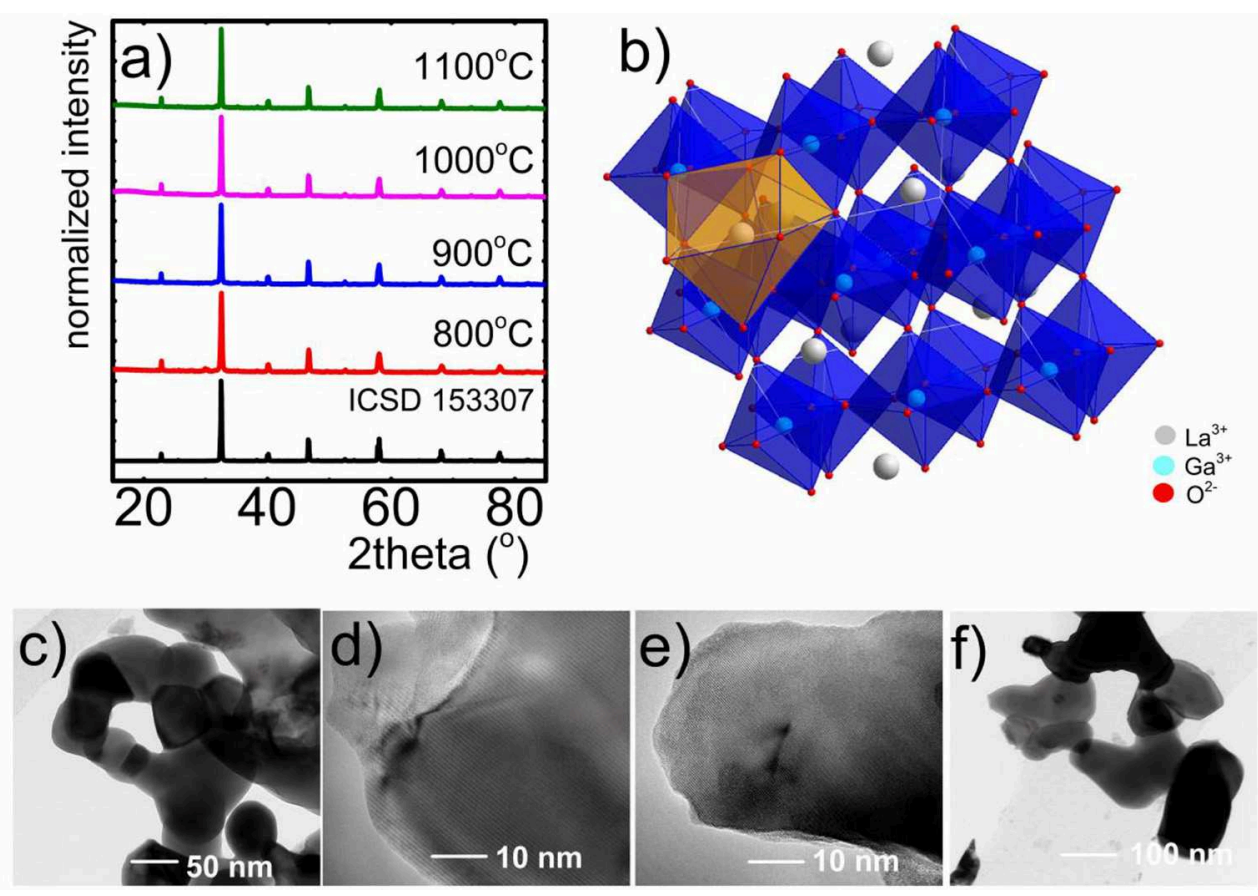

FIGURE 1 | XRD patterns of $\mathrm{LaGaO}_{3}: \mathrm{V}$ nanocrystals synthesized by citric acid-assisted sol-gel method (M:CA 1:1) annealed at different temperatures (a); visualization of $\mathrm{LaGaO}_{3}$ perovskite structure (b); respective TEM images of $\mathrm{LaGaO}_{3}: \mathrm{V}$ nanocrystals with the 10 -fold excess of citric acid, annealed at $800^{\circ} \mathrm{C}$ (c), $900^{\circ} \mathrm{C}$ (d), $1,000^{\circ} \mathrm{C}$ (e), and $1,100^{\circ} \mathrm{C}$ (f).

$\left[\mathrm{Ga}\left(\mathrm{NO}_{3}\right)_{3} \cdot 9 \mathrm{H}_{2} \mathrm{O}\right.$ with $99.999 \%$ purity from Alfa Aesar], ammonium metavanadate $\left(\mathrm{NH}_{4} \mathrm{VO}_{3}\right.$ with $99 \%$ purity from Alfa Aesar) and citric acid $\left(\mathrm{CA}, \mathrm{C}_{6} \mathrm{H}_{8} \mathrm{O}_{7}, 99.5+\%\right.$ purity from Alfa Aesar,) were used as substrates of the reaction. Stoichiometric amount of lanthanum oxide was dissolved in distilled water and ultrapure nitric acid (96\%). The created lanthanum nitrate was recrystallized three times using small quantities of distilled water. After this, adequate quantities of $\mathrm{Ga}\left(\mathrm{NO}_{3}\right)_{3} \cdot 9 \mathrm{H}_{2} \mathrm{O}$ and $\mathrm{NH}_{4} \mathrm{VO}_{3}$ were diluted in distilled water and added to aqueous solution of obtained lanthanum nitrate. The mixture was stirred with citric acid using magnetic stirrer and heated up to $90^{\circ} \mathrm{C}$ for $1 \mathrm{~h}$ to provide the metal complexation process. Afterwards, the solution was dried for 1 week at $90^{\circ} \mathrm{C}$ to create a resin. Finally, the nanocrystals were received by annealing the resin in air for $8 \mathrm{~h}$ at $800,900,1,000$, and $1,100^{\circ} \mathrm{C}$, respectively. The vanadium dopant was used in the amount of $\mathrm{x}=0.1 \%$ in respect to number of moles of $\mathrm{Ga}^{3+}$ ions. The CA were used in different molar ratio in respect to all metals (M), namely $1: 1,2: 1,4: 1,6: 1,8: 1$, and 10:1.

\section{$\mathrm{LaGaO}_{3}: \mathrm{V}$ Synthesis With the Charge Compensation Using $\mathrm{Mg}^{2+}$ and $\mathrm{Ca}^{2+}$ ions}

The $\mathrm{LaGaO}_{3}: \mathrm{V}$ nanocrystals with $\mathrm{Mg}^{2+}$ and $\mathrm{Ca}^{2+}$ ions as a charge compensators have been successfully obtained using the same Pechini method, which was exploited to synthesized the previous presented $\mathrm{LaGaO}_{3}: \mathrm{V}$ powders (Kniec and Marciniak, 2018a). The lanthanum oxide was recrystallized. Appropriate quantities of $\mathrm{Ga}\left(\mathrm{NO}_{3}\right)_{3} \cdot 9 \mathrm{H}_{2} \mathrm{O}, \mathrm{NH}_{4} \mathrm{VO}_{3}$, magnesium nitrate heksahydrate $\left[\mathrm{Mg}\left(\mathrm{NO}_{3}\right)_{2} \cdot 6 \mathrm{H}_{2} \mathrm{O}\right.$ with $99.999 \%$ purity from Alfa
Aesar] or calcium nitrate tetrahydrate $\left[\mathrm{Ca}\left(\mathrm{NO}_{3}\right)_{2} \cdot 4 \mathrm{H}_{2} \mathrm{O}\right.$ with 99.995\% purity from Alfa Aesar] were added to the mixture of all reactants and stirred with citric acid for $1 \mathrm{~h}$ at $90^{\circ} \mathrm{C}$, where the citric acid was used in the 6-fold excess in respect to total amount of metals moles. Than appropriate volume of PEG-200 (1 PEG200: 1 CA) was dropped to the solution. The reaction was carried out for $2 \mathrm{~h}$ with simultaneous heating. After this synthesis the received solutions were dried for 1 week at $90^{\circ} \mathrm{C}$. The powders of $\mathrm{LaGaO}_{3}: \mathrm{V}, \mathrm{Mg}^{2+}\left(\mathrm{Ca}^{2+}\right)$ were finally obtained by annealing in air for $8 \mathrm{~h}$ at $800^{\circ} \mathrm{C}$. The concentration of $\mathrm{V}$ ions was $0.1 \%$ in respect to number of moles of $\mathrm{Ga}^{2+}$ ions, whereas the total amount of $\mathrm{Mg}^{2+}\left(\mathrm{Ca}^{2+}\right)$ was used in the ratio of $1: 1,2: 1,4: 1$, and $8: 1$ in respect to the vanadium ions.

\section{Characterization}

Powder diffraction studies were carried out on PANalytical X'Pert Pro diffractometer equipped with Anton Paar TCU $1000 \mathrm{~N}$ Temperature Control Unit using Ni-filtered $\mathrm{Cu} K \alpha$ radiation ( $V=40 \mathrm{kV}, I=30 \mathrm{~mA})$.

Transmission electron microscopy images were obtained using the Tecnai G2 20 S/TEM Microscope from FEI Company. The microscope was equipped with a thermionic LaB6 emitter and EDS detector for elemental analysis. The study was conducted in the TEM mode at maximum voltage of $200 \mathrm{kV}$. Micrographs were taken at various magnifications, including high resolution images with lattice fringes.

The emission spectra were measured using the $266 \mathrm{~nm}$ excitation line from a laser diode (LD) and a Silver-Nova 

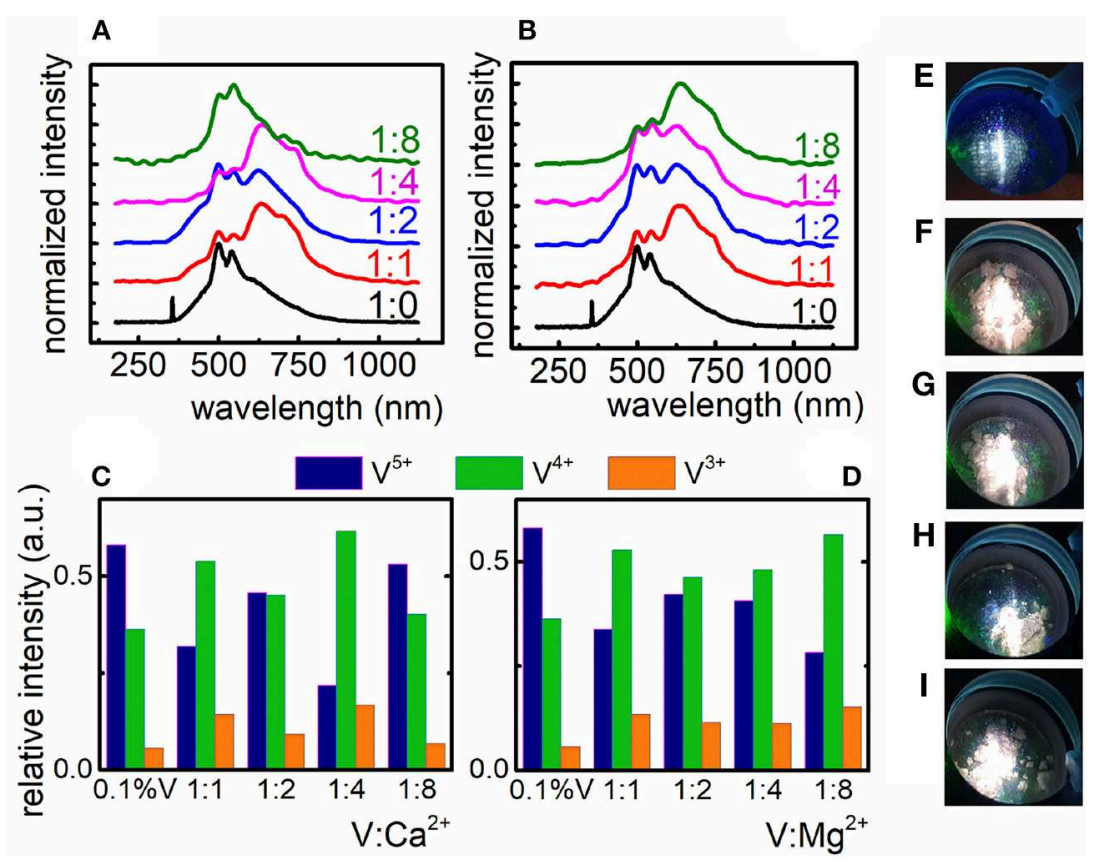

FIGURE 2 | Influence of the $\mathrm{Ca}^{2+}$ (A) and $\mathrm{Mg}^{2+}$ (B) compensating ions on the $\mathrm{V}$ emission spectrum in $\mathrm{LaGaO}_{3}$ nanocrystals; relative emission intensity of the $\mathrm{V}$ ions after charge compensation with $\mathrm{Ca}^{2+}$ (C) and $\mathrm{Mg}^{2+}$ ions (D); emission color of uncompensated $\mathrm{LaGaO}_{3}: \mathrm{V}$ nanocrystals $(\mathbf{E})$ and compensated $\mathrm{LaGaO}_{3}: \mathrm{V}$ nanocrystals with the $\mathrm{V}: \mathrm{Mg}^{2+}$ ratio of 1:1, 1:2, 1:4, and 1:8 (F-I), respectively.

Super Range TEC Spectrometer form Stellarnet (1 nm spectral resolution) as a detector.

\section{RESULTS AND DISCUSSION}

The phase purity and crystalline structure of obtained $\mathrm{LaGaO}_{3}: \mathrm{V}$ powders with different amounts of CA and the employment of charge compensating ions was examined using the XRD analysis (Figure 1a, see also Figures S1, S2). Moreover, the influence of annealing temperature on the $\mathrm{LaGaO}_{3}$ structure, especially on the grain size, was analyzed (Figures 1a,c-f). Comparing the reference peaks (ICSD 153307) with measured XRD patterns it was confirmed that obtained phosphors crystalized in orthorhombic structure and centrosymmetric Pbnm space group. Additional reflection peaks found for the sample annealed at $800^{\circ} \mathrm{C}$, without charge compensation, originate from $\mathrm{La}_{2} \mathrm{O}_{3}$ and $\mathrm{Ga}_{2} \mathrm{O}_{3}$ impurities. These results confirm that the sol-gel citric acid-assisted synthesis with and without charge compensation allows to obtain the $\mathrm{LaGaO}_{3}: \mathrm{V}$ nanocrystals of high structural purity. The analyzed structure consists of 6 -fold coordinated $\mathrm{Ga}^{3+}\left(\mathrm{GaO}_{6}\right)^{9-}$ and 8-fold coordinated $\mathrm{La}^{3+}$ ions, where $\mathrm{La}^{3+}$ sites are situated between slightly tilted and distorted $\left(\mathrm{GaO}_{6}\right)^{9-}$ layers (Marti et al., 1994; Ryba-Romanowski et al., 1999a,b; Kamal et al., 2017; Kniec and Marciniak, 2018a) (Figure 1b). As it was mentioned in the previous work (Kniec and Marciniak, 2018a), due the similarities in valence states and ionic radii between $\mathrm{Ga}^{3+}$ and $\mathrm{V}$ ions $(0.76,0.78,0.72$, and $0.54 \AA$ Kniec and Marciniak, 2018a, for $\mathrm{Ga}^{3+}, \mathrm{V}^{3+}, \mathrm{V}^{4+}$, and $\mathrm{V}^{5+}$, respectively) $\mathrm{V}$ occupy octahedral site of $\mathrm{Ga}^{3+}$ ions in the $\mathrm{LaGaO}_{3}$ matrix.
Representative TEM images of the nanocrystals (Figures 1c-f), which were synthesized using the citric acid-assisted solgel method reveal well-crystalized agglomerated nanoparticles. Additionally it can be noticed that this synthesis method provides higher degree of grains dispersion and their separation in respect to the previously described modified Pechini method (Kniec and Marciniak, 2018a). According to our predictions the increase of annealing temperature results in the enlargement of the average grain size: from $66 \mathrm{~nm}$ for $800^{\circ} \mathrm{C}, 79$ for $900^{\circ} \mathrm{C}, 114 \mathrm{~nm}$ for $1,000^{\circ} \mathrm{C}$ to $145 \mathrm{~nm}$ for $1,100^{\circ} \mathrm{C}$. It is worth mentioning, that the highest grain size of $\mathrm{LaGaO}_{3}: \mathrm{V}$ annealed at $1,100^{\circ} \mathrm{C}$ is more than 2-fold smaller in respect to the counterpart synthesized using Pechini method (381.8 nm) (Kniec and Marciniak, 2018a). However, the increase of CA does not cause the evident changes in grain size.

The first approach employed by us to control the valence state of vanadium ions was compensation method. Two series of nanocrystals with different molar ratio of $\mathrm{Mg}^{2+}$ and $\mathrm{Ca}^{2+}$ ions in respect to the $\mathrm{V}$ ions were prepared. Proposed charge compensation can be written as follows:

$$
2 \times \mathrm{Ga}^{3+} \rightarrow 1 \times \mathrm{V}^{4+}+1 \times \mathrm{Ca}^{2+} / \mathrm{Mg}^{2+}
$$

Two $\mathrm{Ga}^{3+}$ sites were substituted by one $\mathrm{V}^{4+}$ ion and one $\mathrm{Ca}^{2+} / \mathrm{Mg}^{2+}$ ion so that the excess electron could be transferred to the compensating ion. Taking into consideration the structural properties of compensated material, it is worth mentioning, that the introduction of even large excess of $\mathrm{Ca}^{2+} / \mathrm{Mg}^{2+}$ ions does not 


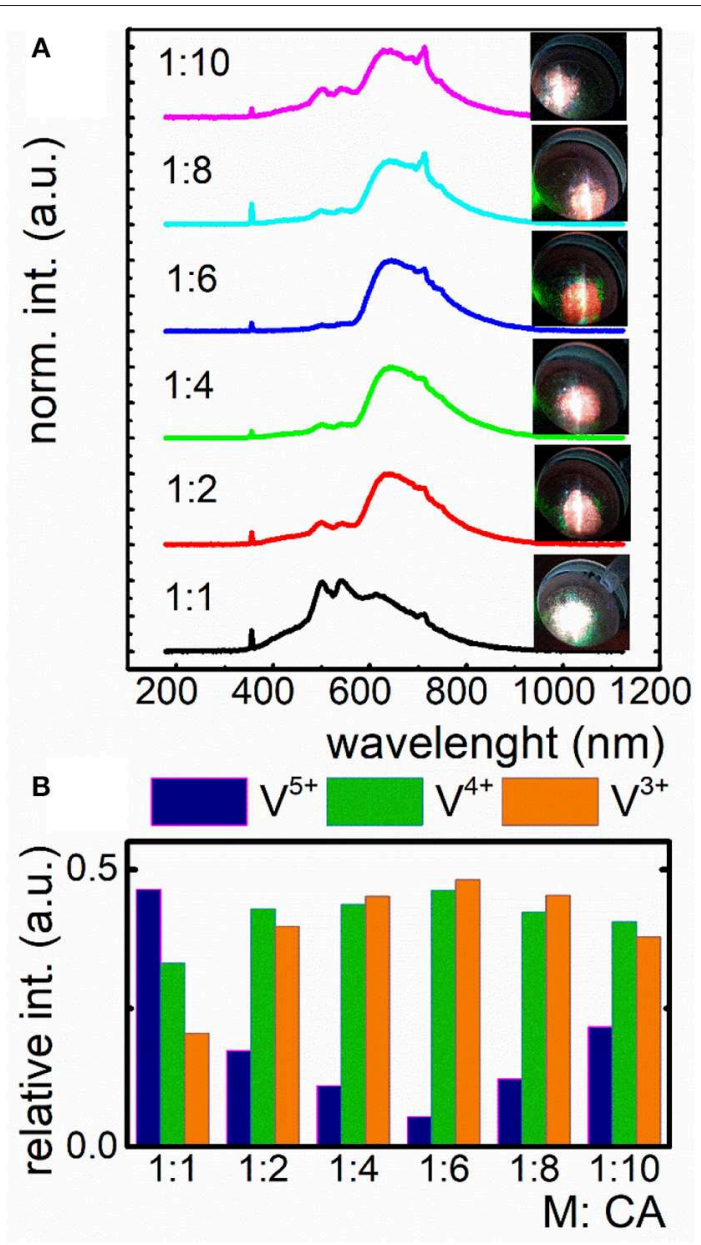

FIGURE 3 | Influence of the different amount of citric acid (CA) in respect to $\mathrm{V}$ ions on the emission spectrum of nanocrystalline $\mathrm{LaGaO}_{3}: \mathrm{V}$ and the corresponding emission color (A); contribution of emission intensity of particular $\mathrm{V}$ ions in the total luminescence of $\mathrm{LaGaO}_{3}: \mathrm{V}$ nanocrystals (B).

influence the changes of XRD patterns (Figure S1). According to our predictions, the introduction of $\mathrm{Mg}^{2+}$ and $\mathrm{Ca}^{2+}$ in the crystal structure caused the rise of the $\mathrm{V}^{4+}$ emission intensity $\left(\lambda_{\mathrm{em}}=633 \mathrm{~nm}\right)$ in respect to the uncompensated counterpart (Figures 2A-D). Due to the fact that no structural changes can be found in the XRD pattern even for high $\mathrm{Ca}^{2+} / \mathrm{Mg}^{2+}$, the observed changes are the confirmation of the successful charge compensation and thus the increase of $\mathrm{V}^{4+}$ concentration. One can notice that even a small addition of $\mathrm{Mg}^{2+}$ and $\mathrm{Ca}^{2+}$ ions to the $\mathrm{LaGaO}_{3}: 0.1 \% \mathrm{~V}$ crystal lattice affects the shape of emission spectra (Figures 2C,D) significantly. It can be found that $\mathrm{Mg}^{2+}$ ions revealed better, in respect to the $\mathrm{Ca}^{2+}$ ions, performance to charge compensation which is reflected in the dominant emission of $\mathrm{V}^{4+}$ ions over the emission of $\mathrm{V}^{3+}$ and $\mathrm{V}^{5+}$ ions for each amount of compensating ion. However, the most satisfactory charge compensation was found in the case of incorporation of 8-fold excess of $\mathrm{Mg}^{2+}$ in respect to $\mathrm{V}$ (Figures 2B,D). This effect may be explained in terms of superior lability of $\mathrm{Mg}^{2+}$ ions in the lattice, which results from their smaller ionic radius $\left(0.78 \AA\right.$ ) compared to $\mathrm{Ca}^{2+}$ ions $(1.06 \AA)$. The impact of the amount of compensating ions on the emission intensity of the particular oxidation state of vanadium ions is presented in Figures 2C,D. In the case of $\mathrm{Mg}^{2+}$ gradual increase of its concentration causes gradual decrease of $\mathrm{V}^{5+}$ emission intensity and enhancement of $\mathrm{V}^{4+}$ intensity while $\mathrm{V}^{3+}$ becomes almost constant. The changes observed in the case of $\mathrm{Ca}^{2+}$ are rather irregular. The consequence of observed charge compensation is the modulation of emission color (Figures 2E-I). It is also worth noting that in the case of calcium ions there is a concentration limit (1:8), above which $\mathrm{V}^{5+}$ emission intensity becomes anew dominant (Figures 2A,C).

The incorporation of compensating ions caused the enhancement of $\mathrm{V}^{4+}$ emission intensity, however the luminescence of both $\mathrm{V}^{5+}$ and $\mathrm{V}^{3+}$ ions is still observed and cannot be completely reduced. The contribution of $\mathrm{V}^{5+}$ emission intensity in the emission spectra of $\mathrm{LaGaO}_{3}: \mathrm{V}$ is relevant and that is why the emission color does not changes significantly (Figures 2E-I) indicating that charge compensation does not provide sufficient ability to modulation of vanadium oxidation states. Based on these results new approach to charge modulation was proposed.

Taking advantage from the fact that PEG, which was used in the case of previously described Pechini method is well-known from its oxidizing properties and may lead to the increase of $\mathrm{V}^{5+}$ concentration, in the second approach we decided to use sol-gel method to eliminate PEG as a reagent, being involved in the resin creation. The issue was to involve all $\mathrm{COOH}$ groups to reduction reaction. $\mathrm{Cit}^{3-}$ ions were used in different molar quantity in respect to the total amount of metal ions (M) in the lattice (Figure 3). To verify the capability of $\mathrm{V}$ oxidation states modulation by the CA concentration, the emission spectra of $\mathrm{LaGaO}_{3}: \mathrm{V}$ nanocrystals were recorded at $-150^{\circ} \mathrm{C}$ under $266 \mathrm{~nm}$ excitation. Low measurement temperature provides the highest emission intensity, being to a lesser extent affected by lattice vibrations, reducing the luminescence temperature quenching (Kniec and Marciniak, 2018a,b). The employment of the same molar amounts of ions and CA caused the presence of three emitting $\mathrm{V}$ oxidation states, namely $\mathrm{V}^{5+}, \mathrm{V}^{4+}$, and $\mathrm{V}^{3+}$, with the predominant emission intensity of $\mathrm{V}^{5+}$. This phenomenon indicates that this molar ratio is insufficient to provide significant reduction of $\mathrm{V}^{5+}$. The employment of 2 -fold excess of CA (1:2) leads to the apparent domination of $\mathrm{V}^{4+}$ emission and thereby the change of emission color (Figures 3A,B), pointing to the immense impact on the $\mathrm{V}$ luminescence properties. Increasing the quantity of capping agent to 6-fold excess in respect to metal ions, the $\mathrm{V}^{5+}$ emission intensity decreases with the simultaneously rise of $\mathrm{V}^{4+}$ and $\mathrm{V}^{3+}$ luminescence (Figure 3B), being a limit value, above which a reversed dependence occurs. This phenomenon determines the color output of $\mathrm{LaGaO}_{3}: \mathrm{V}$, which changes from white to red, while the emission is being redshifted $\left(\mathrm{V}^{4+}\right.$ and $\left.\mathrm{V}^{3+}\right)$ and becomes whitish as the $\mathrm{V}^{5+}$ amount increases (Figure 3A, see also Figures S3, S5). It is worth noting that although initially with the increase of CA concentration the emission intensity of $\mathrm{V}^{5+}$ decreases in respect to the $\mathrm{V}^{4+}$ and $\mathrm{V}^{3+}$, above $1: 8$ ratio the $\mathrm{V}^{5+}$ emission band appears anew. The enhancement of $\mathrm{V}^{5+}$ luminescence may be due the fact, 


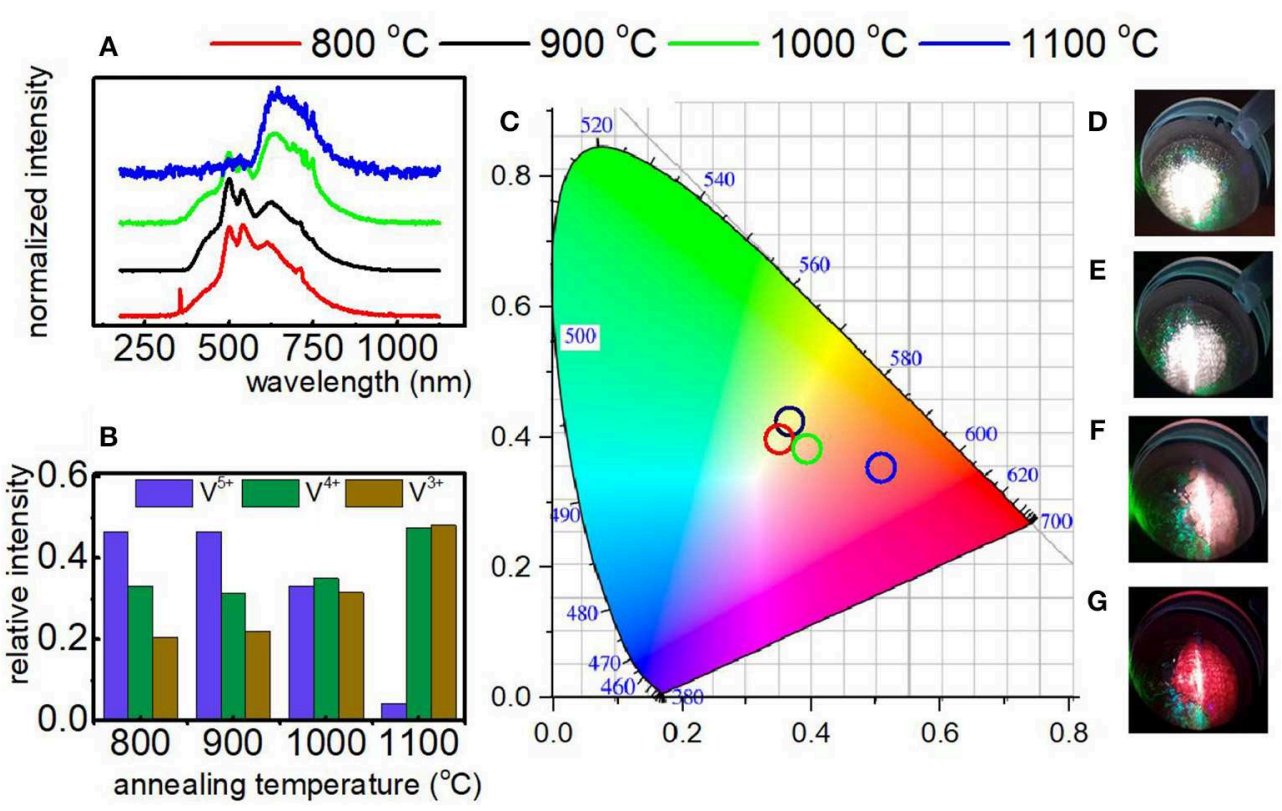

FIGURE 4 | Emission spectrum of $\mathrm{LaGaO}_{3}: \mathrm{V}$ nanocrystals as a function of annealing temperature recorded at $-150^{\circ} \mathrm{C}$ under $266 \mathrm{~nm}$ excitation (A); the relative emission of each $\mathrm{V}$ ions in the $\mathrm{LaGaO}_{3}$ nanocrystals annealed at different temperatures (B); the $\mathrm{CIE} 1,931$ chromatic coordinates calculated for $\mathrm{LaGaO}: \mathrm{V}$ nanocrystals annealed at different temperatures (C); $\mathrm{LaGaO}_{3}: \mathrm{V}$ emission colors at $-150^{\circ} \mathrm{C}$ after annealing at $800,900,1,000$, and $1,100^{\circ} \mathrm{C}$ (D-G), respectively.

that higher content of $\mathrm{Cit}^{3-}$ provides the stabilization of more positive charge on $\mathrm{V}$. In turn the $\mathrm{V}$ charge lowering confirms the reducing properties of $\mathrm{CA}$ even in the nanoscale materials. On the other hand, as it was already proved in the case of nanocrystalline phosphors doped with vanadium ions the $\mathrm{V}^{5+}$ ions are mainly located in the surface part of the grains, while $\mathrm{V}^{4+}$ and $\mathrm{V}^{3+}$ in the core part (Kniec and Marciniak, 2018b). Therefore, the enhancement of the $\mathrm{V}^{5+}$ emission at higher CA concentration may be related with the higher dispersion of the $\mathrm{LaGaO}_{3}$ nanocrystals leading also to the higher separation of the grains. This is in agreement with the TEM images presented in Figure S4. The observed changes of the relative emission intensity of particular $\mathrm{V}$ oxidation state causes modulation of the emission color (Figures 3A,B).

In the course of our studies it was found that in the case of YAG:V and $\mathrm{LaGaO}_{3}: \mathrm{V}$ nanocrystals the vanadium on its higher oxidation state is mainly located at the surface part of the grain. Therefore, in the last approach we verified either size of the nanocrystals may enable the reduction of the $\mathrm{V}^{5+}$ emission intensity in respect to the $\mathrm{V}^{4+}$ and $\mathrm{V}^{3+}$. The size of the nanocrystals was controlled by the annealing temperature for constant molar ratio of $\mathrm{CA}: \mathrm{V}(1: 1)$. As it can be observed the increase of grain size causes gradual increase of bands associated with the ${ }^{2} \mathrm{E} \rightarrow{ }^{2} \mathrm{~T}_{2}$ and ${ }^{1} \mathrm{E}_{2} \rightarrow{ }^{3} \mathrm{~T}_{1 \mathrm{~g}}$ electronic transitions of $\mathrm{V}^{4+}$ and $\mathrm{V}^{3+}$, respectively in respect to the $\mathrm{V}^{4+}$ $\rightarrow \quad \mathrm{O}^{2-}$ band of $\mathrm{V}^{5+}$ (Figure 4A). This is due to the fact that the rise of grain size causes a decrease in the surfaceto-volume ratio of the nanocrystals and thus a drop of the amount of emitting $\mathrm{V}^{5+}$ ions compared to $\mathrm{V}^{4+}$ and $\mathrm{V}^{3+}$ ions. The most apparent emission changes take part by the annealing temperature increase from 1,000 to $1,100^{\circ} \mathrm{C}$, whereas least relevant are between 800 and $900^{\circ} \mathrm{C}$ (Figure 4B), being strictly related to enlargement of the grain size by 42.94 and $2.53 \mathrm{~nm}$, respectively. Therefore, the emission color changes can be observed, ranging from white, connected with the domination of $\mathrm{V}^{5+}$ luminescence, trough pinkish, related to the presence of each $\mathrm{V}$ ions, ending on red color, originating from predominant $\mathrm{V}^{4+}$ and $\mathrm{V}^{3+}$ luminescence (Figures 4B,D-G). This in turn enables the modulation of color output of $\mathrm{LaGaO}_{3}: \mathrm{V}$, which varies depending on the total contribution of each $\mathrm{V}$ ions in the luminescence (Figures 4B,D-G). The contribution of each $\mathrm{V}^{\mathrm{n}+}$ ions into total emission spectra was estimated by the calculation of the integrals in the range of 400-570, 580-675, and 680-750 nm integral emission intensity for $\mathrm{V}^{3+}, \mathrm{V}^{4+}$, and $\mathrm{V}^{5+}$, respectively. In addition, knowing the average grain size of $\mathrm{LaGaO}_{3}: \mathrm{V}$ nanocrystals, the possibility of establishment of the emission spectrum and, consequently, predict the color output was affirmed (Figure 4C). The same dependence, concerning the size effect on the $\mathrm{V}$ oxidation states was also observed for $\mathrm{LaGaO}_{3}: \mathrm{V}$ nanocrystals, where citric acid was incorporated in higher concentration (see Figure S3).

As it can be observed, that all presented approaches led to the decrease of $\mathrm{V}^{5+}$ emission intensity, however the last method, based on the modification of the sizes of the $\mathrm{LaGaO}_{3}$ nanocrystals, is the most efficient.

\section{CONCLUSION}

In this paper three approaches to stabilize and modulate the $\mathrm{V}$ oxidation states in $\mathrm{LaGaO}_{3}$ nanocrystals and thus their emission color have been demonstrated. It was found that in this perovskite lattice three different $\mathrm{V}$ valence states are present, namely $\mathrm{V}^{5+}$, 
$\mathrm{V}^{4+}$, and $\mathrm{V}^{3+}$, showing the emission, being related to the $\mathrm{V}^{4+} \rightarrow$ $\mathrm{O}^{2-} \mathrm{CT}$ transition $\left(\lambda_{\mathrm{em}}=520 \mathrm{~nm}\right),{ }^{2} \mathrm{E} \rightarrow{ }^{2} \mathrm{~T}_{2}\left(\lambda_{\mathrm{em}}=645 \mathrm{~nm}\right)$ and narrow line ${ }^{1} \mathrm{E}_{2} \rightarrow{ }^{3} \mathrm{~T}_{1 \mathrm{~g}}\left(\lambda_{\mathrm{em}}=712 \mathrm{~nm}\right) \mathrm{d}$-d electronic transition, respectively.

Furthermore it was concluded that at $-150^{\circ} \mathrm{C}$ under 266 irradiation $\mathrm{V}^{4+}$ ions exhibit broad band emission, whereas $\mathrm{V}^{3+}$ ions reveals narrow line luminescence. It was presented that three different approaches including the implementation of compensating ions, by altering the ratio of citric acid to metal ions and the tuning of the size of the nanocrystals in range 66-145 $\mathrm{nm}$ through change of annealing temperature in 800$1,100^{\circ} \mathrm{C}$ range may provide the ability to regulate the valence state of vanadium ions. It was found that in the case of charge compensation method the introducing of $\mathrm{Mg}^{2+}$ ions is much more efficient, due the similar ionic radius to $\mathrm{V}$ ions and higher lability of compensating ions in respect to $\mathrm{Ca}^{2+}$. In turn the citric acid-assisted synthesis, where CA was used in the excess in respect to total amount of metals in the lattice, leads to the significant increase of $\mathrm{V}^{4+}$ and $\mathrm{V}^{3+}$ luminescent intensity with the simultaneous improvement of nanocrystals separation and narrower size distribution in respect to the powders obtained using Pechini method. Basing on the fact, that particular oxidation states of $\mathrm{V}$ ions are localized in different part of the $\mathrm{LaGaO}_{3}$ nanocrystals, namely $\mathrm{V}^{5+}$ in the surface, $\mathrm{V}^{4+}$ and $\mathrm{V}^{3+}$ in the core part, respectively, the influence of the grain size of $\mathrm{V}$ emission intensity was investigated. The increase of the annealing temperature and thereby the size of the nanocrystals, leads to the decrease of $\mathrm{V}^{5+}$ luminescence and simultaneously causing the enhancement of $\mathrm{V}^{4+}$ and $\mathrm{V}^{3+}$ ones. The most significant $\mathrm{V}^{5+}$ emission changes are observed when the annealing temperature increase from 1,000 to $1,100^{\circ} \mathrm{C}$, which corresponds to the enlargement of the grain size by $43 \mathrm{~nm}$. All of the presented approaches provide the differences

\section{REFERENCES}

Azkargorta, J., Marciniak, L., Iparraguirre, I., Balda, R., Strek, W., BarredoZuriarrain, M., et al. (2016). Influence of grain size and $\mathrm{Nd} 3+$ concentration on the stimulated emission of $\mathrm{LiLa}_{1-\mathrm{x}} \mathrm{Nd}_{\mathrm{x}} \mathrm{P}_{4} \mathrm{O}_{12}$ crystal powders. Opt. Mater. (Amst). 63, 3-8. doi: 10.1016/j.optmat.2016.07.016

Brik, M. G., Pan, Y. X., and Liu, G. K. (2011). Spectroscopic and crystal field analysis of absorption and photoluminescence properties of red phosphor $\mathrm{CaAl}_{12} \mathrm{O}_{19}: \mathrm{Mn}^{4+}$ modified by MgO. J. Alloys Compd. 509, 1452-1456. doi: 10.1016/j.jallcom.2010.11.117

Brik, M. G., Papan, J., Jovanović, D. J., and Dramićanin, M. D. (2016). Luminescence of $\mathrm{Cr}^{3+}$ ions in $\mathrm{ZnAl}_{2} \mathrm{O}_{4}$ and $\mathrm{MgAl}_{2} \mathrm{O}_{4}$ spinels: correlation between experimental spectroscopic studies and crystal field calculations. J. Lumin. 177, 145-151. doi: 10.1016/j.jlumin.2016.04.043

Buzea, C., Pacheco, I. I., and Robbie, K. (2007). Nanomaterials and nanoparticles: sources and toxicity. Biointerphases 2, MR17-MR71. doi: 10.1116/1.2815690

Cao, R., Ceng, X., Huang, J., Xia, X., Guo, S., and Fu, J. (2016). A double-perovskite $\mathrm{Sr}_{2} \mathrm{ZnWO}_{6}: \mathrm{Mn}^{4+}$ deep red phosphor: synthesis and luminescence properties. Ceram. Int. 42, 16817-16821. doi: 10.1016/j.ceramint.2016.07.173

Cao, R., Zhang, F., Xiao, H., Chen, T., Guo, S., Zheng, G., et al. (2018). Perovskite $\mathrm{La}_{2} \mathrm{LiRO}_{6}: \mathrm{Mn}^{4+}(\mathrm{R}=\mathrm{Nb}, \mathrm{Ta}, \mathrm{Sb})$ phosphors: synthesis and luminescence properties. Inorganica Chim. Acta 483, 593-597. doi: 10.1016/j.ica.2018.09.015.

Chowdhury, S. R., and Yanful, E. K. (2010). Arsenic and chromium removal by mixed magnetite-maghemite nanoparticles and the of $\mathrm{V}$ emission intensity, however the most efficient method based on the modification of the grain size, which is confirmed by the most apparent changes in $\mathrm{LaGaO}_{3}: \mathrm{V}$ color output. Taking into account that different oxidation states of vanadium ions possess favorable optical properties for i.e., lightning and luminescent thermometry, we believe that this study may be of relevant importance for further application of vanadium based nanocrystalline phosphors.

\section{DATA AVAILABILITY}

All datasets generated for this study are included in the manuscript and the Supplementary Files.

\section{AUTHOR CONTRIBUTIONS}

All authors listed have made a substantial, direct and intellectual contribution to the work, and approved it for publication.

\section{ACKNOWLEDGMENTS}

The High Sensitive Thermal Imaging for Biomedical and Microelectronic Application project is carried out within the First Team programme of the Foundation for Polish Science cofinanced by the European Union under the European Regional Development Fund.

\section{SUPPLEMENTARY MATERIAL}

The Supplementary Material for this article can be found online at: https://www.frontiersin.org/articles/10.3389/fchem. 2019.00520/full\#supplementary-material

effect of phosphate on removal. J. Environ. Manage. 91, 2238-2247. doi: 10.1016/j.jenvman.2010.06.003

Davar, F., Hassankhani, A., and Loghman-Estarki, M. R. (2013). Controllable synthesis of metastable tetragonal zirconia nanocrystals using citric acid assisted sol-gel method. Ceram. Int. 39, 2933-2941. doi: 10.1016/j.ceramint.2012.09.067

Devi, P. S., Gafney, H. D., Petricevic, V., and Alfano, R. R. (1996). Synthesis and spectroscopic properties of $\left(\mathrm{Cr}^{4+}\right)$ doped sol-gels. J. Non Cryst. Solids 203, 78-83. doi: 10.1016/0022-3093(96)00336-5

Drabik, J., Cichy, B., and Marciniak, L. (2018). New type of nanocrystalline luminescent thermometers based on $\mathrm{Ti}^{3+} / \mathrm{Ti}^{4+}$ and $\mathrm{Ti}^{4+} / \mathrm{Ln}^{3+}\left(\mathrm{Ln}^{3+}=\mathrm{Nd}^{3+}\right.$, $\mathrm{Eu}^{3+}, \mathrm{Dy}^{3+}$ ) luminescence intensity ratio. J. Phys. Chem. C 122, 14928-14936. doi: 10.1021/acs.jpcc.8b02328

Elzbieciak, K., Bednarkiewicz, A., and Marciniak, L. (2018). Temperature sensitivity modulation through crystal field engineering in $\mathrm{Ga}^{3+}$ co-doped $\mathrm{Gd}_{3} \mathrm{Al}_{5-\mathrm{x}} \mathrm{Ga}_{\mathrm{x}} \mathrm{O}_{12}: \mathrm{Cr}^{3+}, \mathrm{Nd}^{3+}$ nanothermometers. Sens. Actuators B Chem. doi: 10.1016/j.snb.2018.04.157

Felice, V., Dussardier, B., Jones, J. K., Monnom, G., and Ostrowsky, D. B. (2001). Chromium-doped silica optical fibres: influence of the core composition on the $\mathrm{Cr}$ oxidation states and crystal field. Opt. Mater. 16, 269-277. doi: 10.1016/S0925-3467(00)00087-2

Grinberg, M., Lesniewski, T., Mahlik, S., and Liu, R. S. (2017). 3d $\mathrm{d}^{3}$ systemcomparison of $\mathrm{Mn}^{4+}$ and $\mathrm{Cr}^{3+}$ in different lattices. Opt. Mater. 74, 93-100. doi: 10.1016/j.optmat.2017.03.057 
Gupta, S. K., Kadam, R. M., Natarajan, V., and Godbole, S. V. (2014). Oxidation state of manganese in zinc pyrophosphate: probed by luminescence and EPR studies. AIP Conf. Proc. 1591, 1699-1701. doi: 10.1063/1.4873082

Gutierrez, L., Aubry, C., Cornejo, M., and Croue, J. P. (2015). Citrate-coated silver nanoparticles interactions with effluent organic matter: influence of capping agent and solution conditions. Langmuir 31, 8865-8872. doi: 10.1021/acs.langmuir.5b02067

Kamal, C. S., Rao, T. K. V., Samuel, T., Reddy, P. V. S. S. S. N., Jasinski, J. B., Ramakrishna, Y., et al. (2017). Blue to magenta tunable luminescence from $\mathrm{LaGaO}_{3}: \mathrm{Bi}^{3+}, \mathrm{Cr}^{3+}$ doped phosphors for field emission display applications. RSC Adv. 7, 44915-44922. doi: 10.1039/C7RA08864G

Kniec, K., and Marciniak, L. (2018a). Spectroscopic properties of $\mathrm{LaGaO}_{3}: \mathrm{V}, \mathrm{Nd}^{3+}$ nanocrystals as a potential luminescent thermometer. Phys. Chem. Chem. Phys. 20, 21598-21606. doi: 10.1039/C8CP04080J

Kniec, K., and Marciniak, L. (2018b). The influence of grain size and vanadium concentration on the spectroscopic properties of YAG: $\mathrm{V}^{3+}, \mathrm{V}^{5+}$ and YAG: $\mathrm{V}$, $\mathrm{Ln}^{3+}\left(\mathrm{Ln}^{3+}=\mathrm{Eu}^{3+}, \mathrm{Dy}^{3+}, \mathrm{Nd}^{3+}\right)$ nanocrystalline luminescent thermometers. Sensors Actuators B Chem. doi: 10.1016/j.snb.2018.02.189

Mao, Z. Y., and Wang, D. J. (2010). Color tuning of direct white light of lanthanum aluminate with mixed-valence europium. Inorg. Chem. 49, 4922-4927. doi: 10.1021/ic902538a

Mao, Z. Y., Wang, D. J., Lu, Q. F., Yu, W. H., and Yuan, Z. H. (2009). Tunable single-doped single-host full-color-emitting LaAlO3:Eu phosphor via valence state-controlled means. Chem. Commun. 2009, 346-348. doi: $10.1039 / \mathrm{b} 814535 \mathrm{k}$

Marciniak, L., Bednarkiewicz, A., and Strek, W. (2017). The impact of nanocrystals size on luminescent properties and thermometry capabilities of Cr, Nd doped nanophosphors. Sens. Actuators B Chem. 238, 381-386. doi: 10.1016/j.snb.2016.07.080

Marti, W., Fischer, P., Altorfer, F., Scheel, H. J., and Tadin, M. (1994). Crystal structures and phase transitions of orthorhombic and rhombohedral $\mathrm{RGaO}_{3}$ $(\mathrm{R}=\mathrm{La}, \mathrm{Pr}, \mathrm{Nd})$ investigated by neutron powder diffraction. J. Phys. Condens. Matter 6, 127-135. doi: 10.1088/0953-8984/6/1/014

Martínez-Martínez, R., García-Hipólito, M., Ramos-Brito, F., Hernández-Pozos, J. L., Caldiño, U., and Falcony, C. (2005). Blue and red photoluminescence from $\mathrm{Al}_{2} \mathrm{O}_{3}: \mathrm{Ce}^{3+}: \mathrm{Mn}^{2+}$ films deposited by spray pyrolysis. J. Phys. Condens. Matter 17, 3647-3656. doi: 10.1088/0953-8984/17/23/016

Matin, M. A., Islam, M. M., Bredow, T., and Aziz, M. A. (2017). The effects of oxidation states, spin states and solvents on molecular structure, stability and spectroscopic properties of fe-catechol complexes: a theoretical study. $A d v$. Chem. Eng. Sci. 7, 137-153. doi: 10.4236/aces.2017.72011

McKittrick, J., Shea, L. E., Bacalski, C. F., and Bosze, E. J. (1999). Influence of processing parameters on luminescent oxides produced by combustion synthesis. Displays 19, 169-172. doi: 10.1016/S0141-9382(98)00046-8

Pathak, C. S., and Mandal, M. K. (2011). Yellow light emission from $\mathrm{Mn}^{2+}$ doped $\mathrm{ZnS}$ nanoparticles. Optoelectron. Adv. Mater. Rapid Commun. 5, 211-214. doi: 10.1016/j.physe.2008.04.013

Peng, M., and Hong, G. (2007). Reduction from $\mathrm{Eu}^{3+}$ to $\mathrm{Eu}^{2+}$ in $\mathrm{BaAl}_{2} \mathrm{O}_{4}: \mathrm{Eu}$ phosphor prepared in an oxidizing atmosphere and luminescent properties of $\mathrm{BaAl}_{2} \mathrm{O}_{4}$ :Eu. J. Lumin. 127, 735-740. doi: 10.1016/j.jlumin.2007.04.012

Ryba-Romanowski, W., Golab, S., Dominiak-Dzik, G., and Berkowski, M. (1999a). Optical spectra of a $\mathrm{LaGaO} 3$ crystal singly doped with chromium, vanadium and cobalt. J. Alloys Compd. 288, 262-268. doi: 10.1016/S0925-8388(99)00117-6

Ryba-Romanowski, W., Golab, S., Dominiak-Dzik, G., Sokolska, I., and Berkowski, M. (1999b). "Growth and optical properties of chromium doped $\mathrm{LaGaO}_{3}$ crystal," in Proceedings of SPIE-The International Society for Optical Engineering, 43-46. Available online at: https://www.scopus. com/inward/record.uri? eid=2-s2.0-0032669535\&partnerID=40\&md5= 318115d07d121bfee5802f921a39653c

Sato, Y., Kato, H., Kobayashi, M., Masaki, T., Yoon, D. H., and Kakihana, M. (2014). Tailoring of deep-red luminescence in $\mathrm{Ca}_{2} \mathrm{SiO}_{4}: \mathrm{Eu}^{2+}$. Angew. Chem. Int. Ed. 53, 7756-7759. doi: 10.1002/anie.201402520

Scharf, B., Clement, C. C., Zolla, V., Perino, G., Yan, B., Elci, S. G., et al. (2014). Molecular analysis of chromium and cobalt-related toxicity. Sci. Rep. 4:5729. doi: 10.1038/srep05729

Shinohara, S., Eom, N., Teh, E. J., Tamada, K., Parsons, D., and Craig, V. S. J. (2018). The Role of citric acid in the stabilization of nanoparticles and colloidal particles in the environment: measurement of surface forces between hafnium oxide surfaces in the presence of citric acid. Langmuir 34, 2595-2605. doi: 10.1021/acs.langmuir.7b03116

Struve, B., and Huber, G. (1985). The effect of the crystal field strength on the optical spectra of $\mathrm{Cr}^{3+}$ in gallium garnet laser crystals. Appl. Phys. B Photophys. Laser Chem. 36, 195-201. doi: 10.1007/BF00704574

Thio, B. J., Montes, M. O., Mahmoud, M. A., Lee, D. W., Zhou, D., and Keller, A. A. (2011). Mobility of capped silver nanoparticles under relevant conditions. Environ. Sci. Technol. 46, 6985-6991. doi: 10.1021/es20 3596w

Trejgis, K., and Marciniak, L. (2018). The influence of manganese concentration on the sensitivity of bandshape and lifetime luminescent thermometers based on $\mathrm{Y}_{3} \mathrm{Al}_{5} \mathrm{O}_{12}: \mathrm{Mn}^{3+}, \mathrm{Mn}^{4+}, \mathrm{Nd}^{3+}$ nanocrystals. Phys. Chem. Chem. Phys. 20, 9574-9581. doi: 10.1039/c8cp00558c

Wang, M. Q., Li, H., He, Y. D., Wang, C., Tao, W. J., and Du, Y. J. (2012). Efficacy of dietary chromium (III) supplementation on tissue chromium deposition in finishing pigs. Biol. Trace Elem. Res. 148, 316-321. doi: 10.1007/s12011-012-9369-x

Weber, M. J., and Riseberg, L. A. (1971). Optical spectra of vanadium ions in yttrium aluminum garnet. J. Chem. Phys. 55, 2032-2038. doi: $10.1063 / 1.1676370$

Zhang, J., and Gao, L. (2004). Synthesis and characterization of nanocrystalline tin oxide by sol-gel method. J. Solid State Chem. 177, 1425-1430. doi: 10.1016/j.jssc.2003.11.024

Zhang, J., Zhang, G. X., Cai, G. M., and Jin, Z. P. (2018). Reduction of Ce(IV) to $\mathrm{Ce}(\mathrm{III})$ induced by structural characteristics and performance characterization of pyrophosphate $\mathrm{MgIn}_{2} \mathrm{P}_{4} \mathrm{O}_{14}$-based phosphors. J. Lumin. 203, 590-598. doi: 10.1016/j.jlumin.2018.07.015

Zhang, Y., Li, X., Li, K., Lian, H., Shang, M., and Lin, J. (2015). Crystal-site engineering control for the reduction of $\mathrm{Eu}^{3+}$ to $\mathrm{Eu}^{2+}$ in $\mathrm{CaYAlO}_{4}$ : structure refinement and tunable emission properties. ACS Appl. Mater. Interfaces 7, 2715-2725. doi: 10.1021/am508859c

Conflict of Interest Statement: The authors declare that the research was conducted in the absence of any commercial or financial relationships that could be construed as a potential conflict of interest.

Copyright (c) 2019 Kniec and Marciniak. This is an open-access article distributed under the terms of the Creative Commons Attribution License (CC BY). The use, distribution or reproduction in other forums is permitted, provided the original author(s) and the copyright owner(s) are credited and that the original publication in this journal is cited, in accordance with accepted academic practice. No use, distribution or reproduction is permitted which does not comply with these terms. 